\title{
Optimal number and location of UPFC devices to enhence voltage profile and minimizing losses in electrical power systems
}

\author{
Sekhane Hocine, Labed Djamel \\ Department of Electrical Engineering, Frère Mentouri Constantine University, \\ Laboratory of Electrical Engineering of Constantine (LGEC), Algeria
}

\section{Article Info \\ Article history: \\ Received Sep 15, 2018 \\ Revised Apr 25, 2019 \\ Accepted May 6, 2019}

\section{Keywords:}

FACTS devices

Genetic algorithm (GA)

Maximum number

Optimal location

Optimal number

Optimal size

UPFC device

\begin{abstract}
The fast increase of loads around the world has made electrical networks more and more complex and difficult to operate close to its capacities. This is has led to many problems such as voltage collapse and energy losses. Therefore, flexible alternating current transmission systems (FACTS) are considred as a best solution for solving these problems. Unified Power Flow Controller UPFC is one of the most important and powerful FACTS devices due to its ability to increase the transmission capacity of the power system and reduce the total line losses. The problem of optimizing its number, location and size has become an important requirement for best advantages of this device. In this paper, a proposed relationship to identify the maximum number of FACTS devices that can be installed for a given power network is introduced in the search process code to determine the optimal number, optimal placement and size of UPFC device to enhance voltages profile and reduce overall system losses in the standard IEEE 14 bus test system using genetic algorithm (GA). The obtained results show clearly that all control parameters of UPFCs in each case are within their limits, and whenever the number of UPFCs installed increases, both voltage deviation and total losses well decreases. They also show that the application of the proposed relationship in the search process code facilitates greatly the search for optimal number, optimal placement and size of UPFC devices and reduces the calculation time. On the other hand, the obtained results has been scientifically justified and compared with other works reported in the literature.
\end{abstract}

Copyright $\odot 2019$ Institute of Advanced Engineering and Science. All rights reserved.

\section{Corresponding Author:}

Sekhane Hocine,

Department of Electrical Engineering,

Frère Mentouri Constantine University,

Laboratory of Electrical Engineering of Constantine (LGEC),

Constantine 25000, Algeria.

Email: docsekhoc@gmail.com

\section{INTRODUCTION}

In recent years, and with the continued growth in energy demand, electrical networks around the world have become suffer various problems such as voltage collapse incidents and increased power system losses [1, 2]. It is of a great probability that voltage instability can occur if the power system is heavily charged, or there is a deficiency of reactive energy in a local area of the power network [3]. Therefore, Flexible Alternating Current Transmission Systems called FACTS is one of the best solutions for solving the voltage collapse problem and minimizing line losses by its provided compensation. These devices use modern power electronics technologies that offer to the electrical networks the ability to control with efficiency the various electrical quantities (real and reactive powers, bus voltage, phase angle, etc), and to improve stability and powers transfer capacity [4]. Unified Power Flow Controller UPFC is one of the most important and powerful 
FACTS devices [5] in view of the possibility of installing it in the electrical networks in order to simultaneously control bus voltage, line impedance and phase angle [6]. Furthermore, UPFC can increase the transmission capacity of the power system and reduce the total line losses through the power oscillation damping [7-9].

The problem of optimizing the location, number and size of FACTS devices have become an important requirement for a best advantages of these devices in order to achieve a number of a desired objective functions $[10,11]$. The optimization strategy is crucially used to specify secure states and economic accounts [12, 13], and from which controllable quantities are adjusted in order to optimize one or more objective functions provided that a set of physical and operational constraints must be respected [14, 15]. In the early eighties, and in order to get round the disadvantages of conventional optimization methods, researchers developed other more efficient and robust techniques called heuristic optimization methods characterized by their ability to quickly find the global optimality of a larger solution space, among them: Particle Swarm Optimization (PSO), Bat Algorithm, Cuckoo Search Algorithm [16], Genetic Algorithm, etc.

In the literature, there are several works on the research field of optimal location and setting of FACTS devices using different optimization methods. In [17], the optimal location and sizing of combination of two FACTS devices (TCPST and TCSC) is studied using PSO algorithm to control the voltage profile and power losses problem in the standard IEEE 30 bus test system. The optimal location and settings of SVC and TCSC devices have been investigated in [10] as a real multi-objective optimization problem using Non-dominated sorting particle swarm optimization method (NSPSO). Firstly, the optimization problem has been formulated as a bi-objective optimization problem considering only the minimization of real power losses (RPL) and the maximization of static voltage stability margin (SVSM). Inthe second step, the problem has been formulated as a three-objective optimization problem, considering also, the minimization of voltage deviation in load buses (LVD). Authors in [5] has used genetic algorithm (GA) to determine the optimal location and values of UPFC device to achieve the following objectives: improve voltages profile, reduce power losses, treatment of power flow in overloaded transmission lines and reduce power generation, in the iraki local network (Diyala $132 \mathrm{kV}$ ). Authors in [7] have proposed the use of genetic algorithm to determine the optimal location and parameter setting of UPFC devices in order to minimizing active power losses in the transmission lines for three standards electrical networks as follows: 3 UPFCs for the IEEE 14 bus, 5 UPFCs for the IEEE 30 bus and 7 UPFCs for the IEEE 57 bus.

The originality of this paper is represented in the application of the relationship of the proposed approach: "Maximum number of FACTS devices that can be installed for a given power network", in the search process to determine the optimal number of UPFC devices as well as the optimal placement and setting of their three parameters (voltage magnitude, phase angle and shunt reactive current) in each case (number of UPFCs) to enhance the voltages profile and reduce overall system losses in the standard IEEE 14 bus test system. It should be mentioned that the search for the optimal number of UPFCs in this paper is based purely on the technical enhancement of the two previous objectives and does not take into account the costs related to the number of UPFCs. Genetic algorithm (GA) is applied in the studied power system in the heavy load condition. In the search process, the step size of the load factor is chosen small (0.01) to obtain a hight quality results.

The obtained results show that all control parameters of UPFCs in each case are within their limits and there is no any violation, which confirms the capacity of each UPFC device installed in its position to operate safely, and this is what strengthens the performance indicator of GA search process in finding the optimal locations of UPFC devices with respecting its limits. On the other hand, it can be seen that whenever the number of UPFCs installed increases, both voltage deviation and total losses well decreases. In addition, the comparison of our results to those reported in the literature indicates that are very close. Furthermore, the application of the relationship of the proposed approach in the search process code makes the calculations limited within a narrow space and therefor facilitates the search for optimal number, optimal placement and size of UPFC devices and reduces the calculation time. Moreover, the proposed calculation method can be very useful especially in case of complex and large scale networks, multi-type FACTS devices...etc.

\section{MODELING OF UPFC}

In 1991 Gyugyi was proposed the Unified Power Flow Controller concept called UPFC [18]. UPFC is a power electronics-based system which can provide simultaneous control of the transmission line impedance, phase angle, voltage magnitude and active and reactive power flow [19, 20].

As it is shown in Figure 1(a), the basic structure of UPFC device is a combination of two compensators: one connected in parallel called STATic COMpensator (STATCOM) and the other in series called Static Synchronous Series Compensator (SSSC). Both compensators are coupled via a common "DC" link to exchange the real power between the output terminals of STATCOM and SSSC [18]. The real power 
demanded by SSSC is drawn by STATCOM from the AC network and supplied to bus $j$ through the DC link. Furthermore, the output voltage of SSSC is added to boost the nodal voltage at bus $j$. in addition to the role of SSSC in the exchange of active power with the AC network, the shunt converter (STATCOM) generate or absorb reactive power in order to provide independent voltage magnitude regulation at the bus where it is connected with the AC network [20].

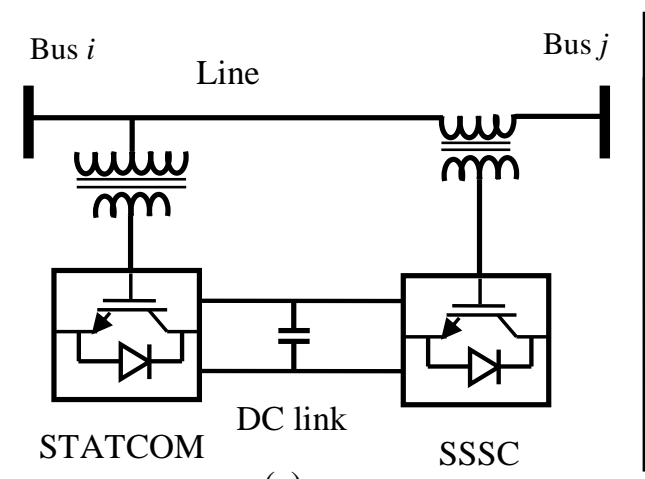

(a)

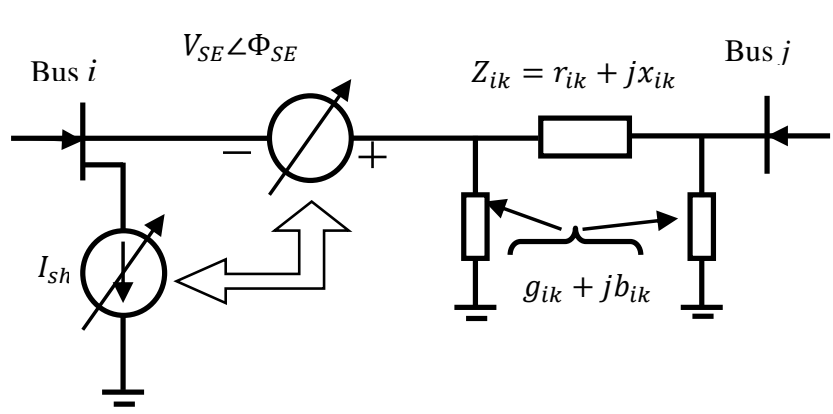

(b)

Figure 1. (a) Basic structure of UPFC connected to the AC network; (b) UPFC equivalent circuit

The equivalent circuit of UPFC is presented in Figure 1(b). The series part is modeled by a controllable voltage source $V_{s e}$, and the shunt part is modeled by a controllable current source $I_{c h}$ [7]. UPFC has three controllable parameters namely: voltage magnitude $V_{s e}$, phase angle $\Phi_{s e}$ of the voltage $V_{s e}$ and shunt reactive current $I_{s h} . V_{s e}$ is injected in series with the transmission line with the ranges $\left[0, V_{s e-\max }\right]$ and provides the voltage regulation while the angle $\Phi_{s e}$ is used for the phase regulation with the ranges $[0,2 \pi]$ and $I_{s h}$ with the ranges $\left[-I_{s h-\max }, I_{s h-\max }\right][7,20,21,22]$.

Based on the equivalent circuit of UPFC shown in Figure 1(b). above, the active and reactive power injection equations at buses $i$ and $j$ are given by the following expressions [23]:

$$
\begin{aligned}
& P_{i_{-} i n j}=G_{F} V_{s e}^{2}+2 V_{i} V_{s e} G_{F} \cos \left(\delta_{i}-\Phi_{s e}\right)-V_{j} V_{s e}\left(G \cos \left(\delta_{j}-\Phi_{s e}\right)-B \sin \left(\delta_{j}-\Phi_{s e}\right)\right) \\
& Q_{i_{-} i n j}=-V_{i} I_{s h}+V_{i} V_{s e}\left(G_{F} \cos \left(\delta_{i}-\Phi_{s e}\right)-B_{F} \sin \left(\delta_{i}-\Phi_{s e}\right)\right) \\
& P_{j_{-} i n j}=-V_{j} V_{s e}\left(G \cos \left(\delta_{j}-\Phi_{s e}\right)+B \sin \left(\delta_{j}-\Phi_{s e}\right)\right) \\
& Q_{j_{-} i n j}=-V_{j} V_{s e}\left(G \cos \left(\delta_{j}-\Phi_{s e}\right)-B_{F} \sin \left(\delta_{j}-\Phi_{s e}\right)\right)
\end{aligned}
$$

with:

$$
\begin{aligned}
& G_{F}=g_{i j}+G \\
& B_{F}=b_{i j}+B \\
& -V_{i} I_{s h}=Q_{s h}
\end{aligned}
$$

$Q_{s h}$ is the reactive power injected by shunt current source in bus $i$.

\section{GENETIC ALGORITHM PROCESS AND PROBLEM FORMULATION}

\subsection{Genetic algorithm process}

Genetic Algorithm (GA) is considered as one of the most important evolutionary algorithms based on mechanism of natural selection and genetics for solving the constrained and unconstrained optimization problems $[24,25]$. It is worth noting that GA can search simultaneously several possible solutions without require to prior knowledge or special properties of the objective function [24, 26, 27]. The individuals are simplified to a chromosome and the strength of an individual is the objective function that must be optimized. The main steps of research mechanism by GA are explained as follows: 


\subsubsection{Initialize a population of chromosomes}

Firstly, the algorithm generates an initial population of a random size [7, 24]. For more explanation, assume two individuals (chromosomes) as an initial population as shown in Figure 2(a). Each individual (chromosome) is designated by a string in binary or real coding, for example if we search for the optimum of a function of $n$ variables $f\left(x_{1}, x_{2}, \ldots, x_{n-1}, x_{n}\right)$ we can simply use a chromosome containing the $n$ variables as depicted in Figure 2(b). With this coding type (real coding), the chromosomes evaluation procedure is faster thanks to the absence of the trans-coding step (from binary to real).

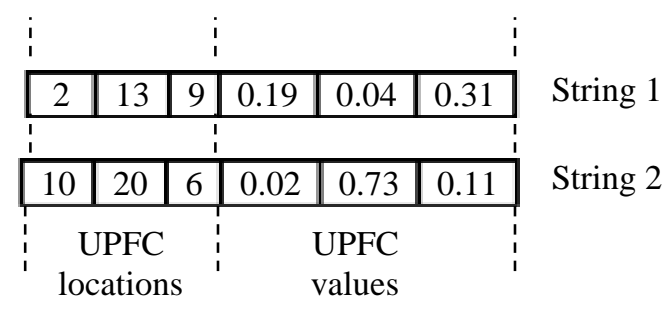

(a)

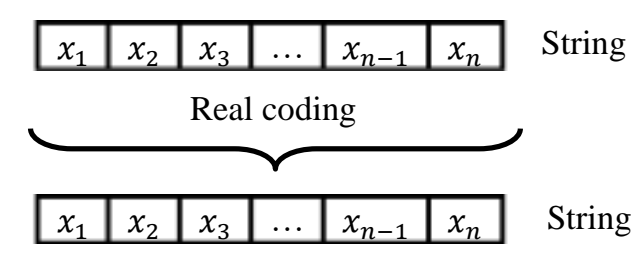

(b)

Figure 2. (a) Two original chromosomes (individuals); (b) Real coding of one chromosome with $n$ variables

\subsubsection{Creating new chromosomes by mating current chromosomes}

In this step, the genetic algorithm uses the individuals in each current generation to produce the next population (new population) by performing the following steps:

a. Fitness calculation: Calculation of the fitness value for each individual of the current population.

b. Selection: The algorithm performs the selection of individuals based on their fitness value. The individuals with better fitness in the current population are more likely to be copied in the second generation. The selected individuals are called parents in the current population or called also elite children to the next population [28].

c. Genetic Operations: In these operations children are generated from parents by one of the following methods:

1) Crossover: Like in the nature, in order to create new chromosomes or children a pairs of parents (original chromosomes) in the current population are combined as depicted in Figure 3(a). The crossover between the pairs of parents generate new individuals (chromosomes or children) that have randomly some parts of both parent's genetic material [5, 28, 29].

2) Mutation: Mutation children are created by changing randomly the genes of a single individual parent as seen in Figure 3(b). Mutation introduces in the population some diversification to avoid premature convergence to the local optimum $[24,26]$.

d. Replacement: In this step the current population must be replaced with the selected children to form the next generation.

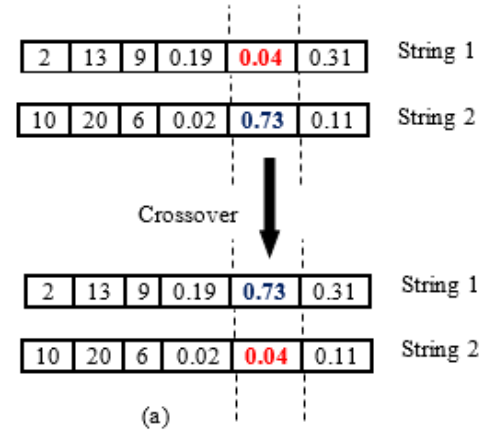

(a)

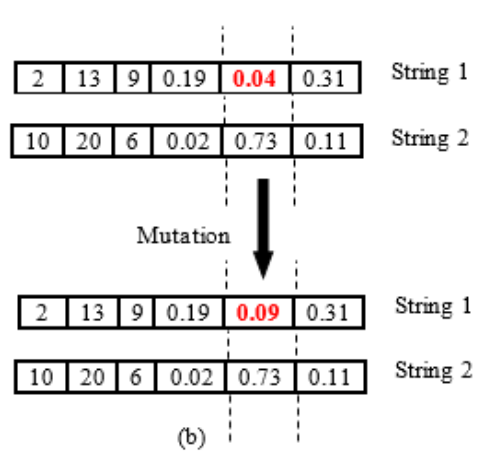

(b)

Figure 3. (a) Crossover operation; (b) Mutation operation

\subsubsection{Stop criteria}

The stopping of the algorithm rely on if one of the stopping criteria is met such as the number of generations, fitness limit and time limit [28, 30]. 


\subsection{Problem formulation}

The main aim of the proposed method is to optimize the number, placement and size of UPFC devices in order to enhance voltage profile and to reduce total line losses of the considered power system. In this respect, the considered optimization is relying on the maximization of the system loadability in which all thermal and voltage constraints are respected. In order to achieve this goal the load factor $(\lambda)$ of the network will be increased in an iterative optimization process.

In the optimization process, generators are modeled as $P V$ buses while loads are modeled as $P Q$ buses. The increase in the active and reactive loads of the power system leads to the voltage collapse [10].

$$
\begin{aligned}
& P_{L}=\lambda P_{L 0} \\
& Q_{L}=\lambda Q_{L 0}
\end{aligned}
$$

where:

$P_{L 0} \& Q_{L 0}$ are the initial active and reactive loads.

$P_{L} \& Q_{L}$ are the active and reactive loads at $P Q$ buses.

To obtain a high quality results, the step size of the load factor is chosen small $(\lambda=0.01)$ for each iteration. The initial load factor is considered as $\lambda_{0}=1$, therefore in the iteration process:

$$
\lambda_{\text {next }}=\lambda_{\text {current }}+0.01
$$

The objective function that maximizes the loadability of the power system can be formulated as follows:

$$
f=\max (\lambda)
$$

In order to keeping a stable operation of the power system, the voltage, active and reactive powers at the outputs of all generators including the slack bus must be restricted by the lower and upper limits indicated as follows:

$$
\begin{aligned}
& V_{G i}^{\min } \leq V_{G i} \leq V_{G i}^{\max } ; i \in N G \\
& P_{G i}^{\min } \leq P_{G i} \leq P_{G i}^{\max } ; i \in N G \\
& Q_{G i}^{\min } \leq Q_{G i} \leq Q_{G i}^{\max } ; i \in N G
\end{aligned}
$$

with:

$N G$ is the number of generators.

On the other hand, the security constraints means the restriction of voltage magnitude at all load buses within its lower and upper operating limits as well as the restriction of transmission lines loading by its maximum capacity limits as expressed in the following equations:

$$
\begin{aligned}
& V_{L i}^{\min } \leq V_{L i} \leq V_{L i}^{\max } ; i \in N L \\
& S_{L i} \leq S_{L i}^{\max } ; i \in N B
\end{aligned}
$$

with:

$N L$ is the number of load buses.

$N B$ is the number of buses.

Furthermore, in the optimization strategy for the placement of UPFC devices using GA, the number of individuals is calculated for a population according to the following equation [7, 31]:

$$
n_{\text {ind }}=3 * n_{U P F C} * n_{\text {plcmt }}
$$

where:

$n_{U P F C}$ is the number of UPFC devices taken on the current optimization process.

$n_{\text {plcmt }}$ is the total number of locations where UPFC devices can be installed. 
On the other hand, the relationship of "the limit number of FACTS devices" approach (maximum number of UPFC devices) that can be installed for a given power network used in the search process code in our study is given by [32]:

$$
n_{U P F C}^{\max }=N b r-N B+1
$$

where:

$\mathrm{Nbr}$ is the total number of branches (lines) of the network.

Finally, the optimization strategy of our study according to GA is summarized in the Figure 4.

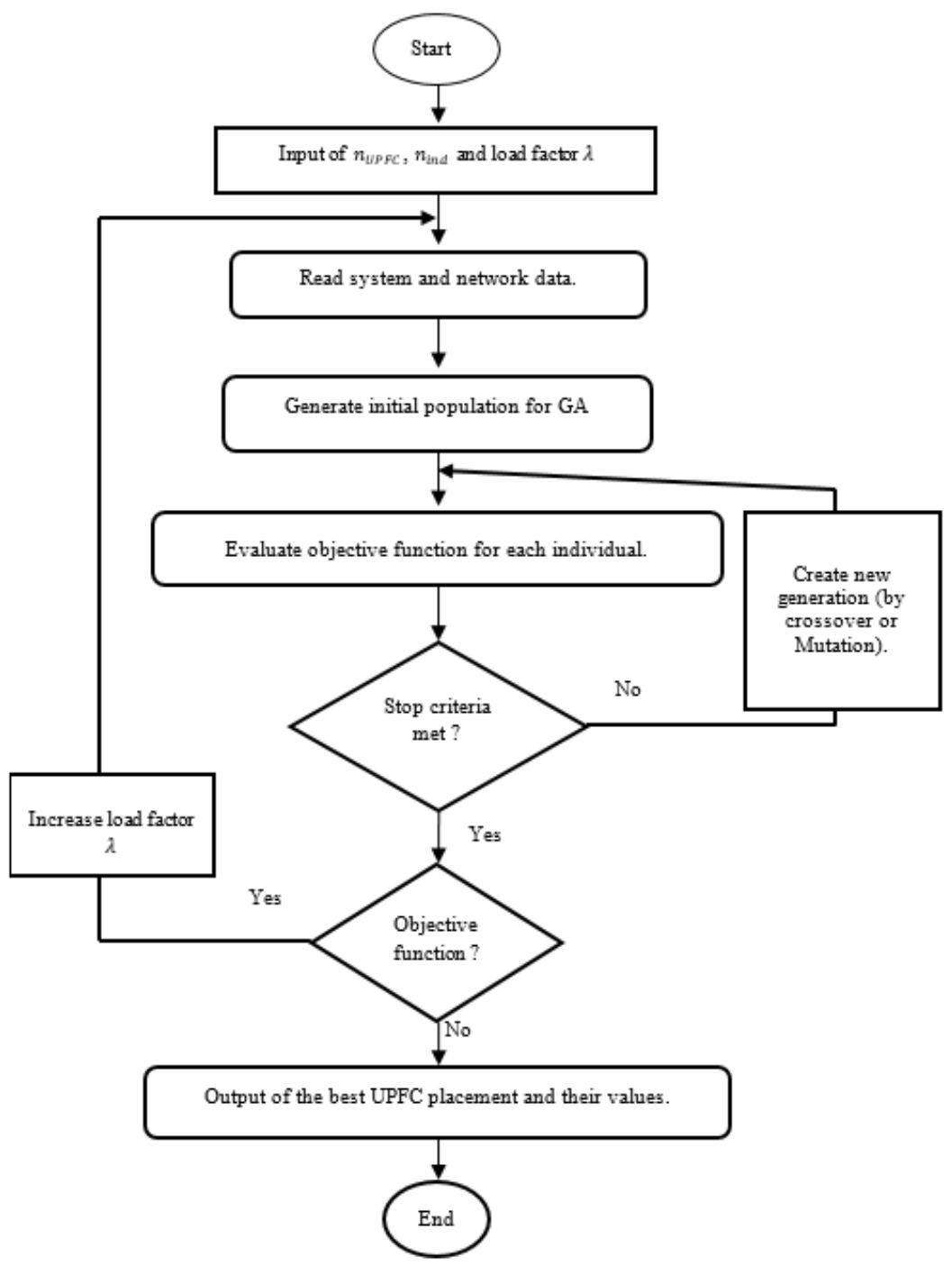

Figure 4. Optimization process flowchart of UPFC placement according to GA

\section{APPLICATION RESULTS AND DISCUSSION}

As it has been clarified in the abstract, the proposed genetic algorithm (GA) and the limit number of FACTS devices" approach are applied to the 14-bus test power system in order to find the optimal number, size and location of UPFC devices for reaching both objectives: minimize voltage deviation (enhance voltage profile) and total losses.

As it is described in [1,33] and [34], IEEE 14-bus test system consists of five generators at buses 1, $2,3,6$, and 8, twenty transmission lines, three transformers with off-nominal tap ratio at lines (4-7), (4-9) and (5-6), and nine loads at buses $4,5,7,9,10,11,12,13$ and 14. The line data, bus data, load data, 
generator data and minimum and maximum limits are detailed in [35]. The single line diagram of IEEE 14bus test system is depicted in Figure 5.

Genetic algorithm technique was implemented in a developed code written in MATLAB environment with the tunable parameters summarized in the Table 1. In this study the limit parameters of one single UPFC are taken from [22] and are tabulated in the Table 2.

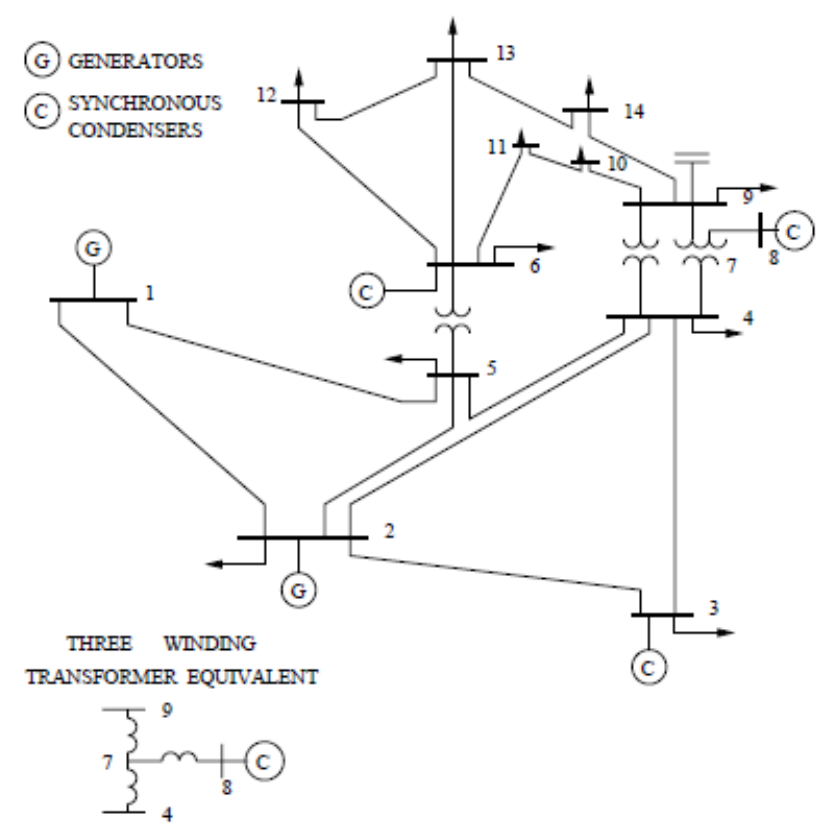

Figure 5. Single line diagram of IEEE 14-bus test system [1]

Table 1. Appropriate Parameters Used in GA Technique

\begin{tabular}{ll}
\hline Parameter & Value \\
\hline Number of generations & 120 \\
Initial population size & 15 \\
Number of elite children & 5 \\
Crossover fraction & 0.8 \\
Fitness limit & $1 e^{-6}$ \\
Time limit & $\infty$ \\
\hline
\end{tabular}

Table 2. Limits Parameters of One Single UPFC

\begin{tabular}{ccc}
\hline & Min & Max \\
\hline$V_{s e}(p . u)$ & 0 & 0.3 \\
$\Phi_{s e}(p . u)$ & 0 & $2 \pi$ \\
$I_{s h}(p . u)$ & -0.15 & +0.15 \\
\hline
\end{tabular}

where

Min: Lower limit value;

Max: Upper limit value;

$V_{s e}$ : Voltage magnitude (of the series part of UPFC);

$\Phi_{s e}$ : Phase angle of the voltage $V_{s e}$;

$I_{s h}:$ Shunt reactive current; $p . u$ : per unit.

On the other hand, the application of the relationship of "the maximum number of UPFC devices" approach considered in the optimal number search process for the studied network yields:

$$
n_{U P F C}^{\max }=N b r-N B+1=20-14+1=7
$$

Therefore, the maximum number of UPFC devices used in the search process code of our study is 7 .

In order to verify the performance of UPFC device on the minimization of voltage deviation and total losses as well as the effect of increase of number of UPFCs on the studied network, GA search procedure is started from the initial load factor $\lambda_{0}=1$ (normal state), then the power system loading increases with a precise step size $\left(\lambda_{\text {step }}=0.01\right)$ until reaching $\lambda=1.7$ (heavy state) to obtain a better outcomes. After running the search process code, the obtained results of optimal location and size of UPFCs for each case (each case designates a number of UPFCs) are organized in Table 3. 
Table 3. Optimal location and controllable parameters according to the number of UPFCs in the 14 bus power test system

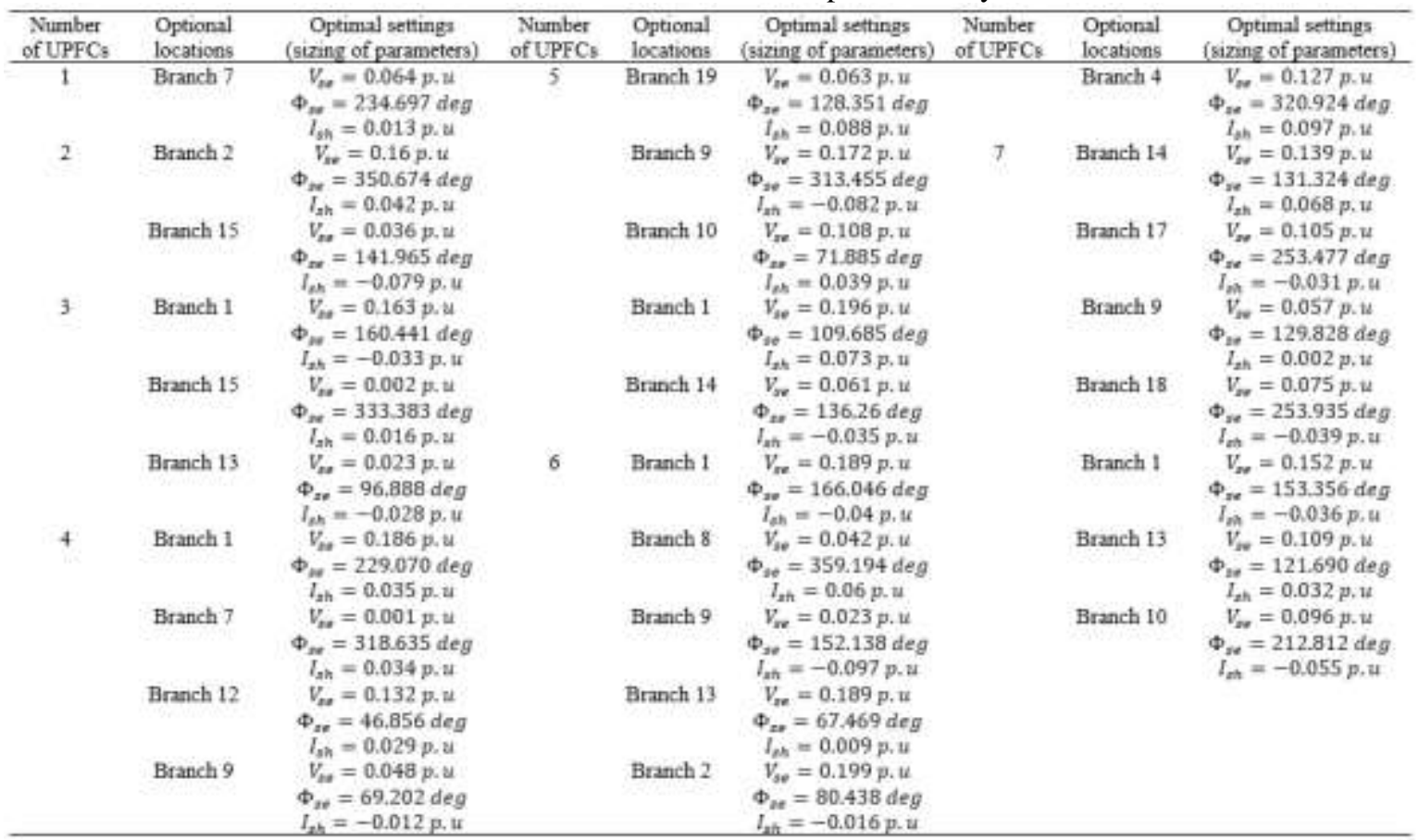

From Table 3, it appears clearly that all control parameters $\left(V_{s e}, \Phi_{s e}\right.$ and $\left.I_{s h}\right)$ are within its limits mentioned in Table 2, and there is no any violation in the three parameters, which confirms the possibility and the capacity of each UPFC device installed in its location to operate safely, and in addition this is what strengthens the performance indicator of GA search process in finding the optimal location of UPFC devices with respecting its limits. It is worth to mention that in the optimal placements results found in Table 3 by GA search process it is remarked that no more than one UPFC is installed in only one branch.

In order to highlighting the influence of number of UPFCs devices on voltage deviation and total lines losses in the studied network, the obtained results after the maximum loading $(\lambda=1.7)$ of the power system without FACTS and with each number of UPFCs devices installed in their optimal locations found in the previous Table 3 are summarized in Table 4.

Table 4. Voltage Deviation and Total Active Losses for Different Number of UPFCs Devices

\begin{tabular}{ccccccccc}
\hline Number of UPFCs & 0 (Without FACTS) & 1 & 2 & 3 & 4 & 5 & 6 & 7 \\
\hline VD (p.u) & 0.017 & 0.015 & 0.006 & 0.005 & 0.003 & $0.003 \ldots$ & $0.003 \ldots$ & $0.003 \ldots$ \\
TL (MW) & 64.15 & 63.13 & 62.55 & 62.02 & 61.64 & $61.6 \ldots$ & $61.6 \ldots$ & $61.6 \ldots$ \\
\hline
\end{tabular}

VD: Voltage Deviation; TL: Total Losses.

At the first glance of Table 4, it appears obviously that both voltage deviation and total losses are well minimized by using a single UPFC compared to case 0 (without FACTS), which indicates the good effect of the device on the enhancement of voltage profile (without FACTS VD $=0.017$ pu and become $0.015 \mathrm{pu}$ with $1 \mathrm{UPFC}$ ) and especially on total losses minimization with an important value of (1.02 MW).

It can be seen also that whenever the number of UPFCs $\left(n_{u p f c}\right)$ installed in the network increases, the voltage deviation (VD) and total losses (TL) decrease, i.e. that $n_{u p f c}$ is inversely proportional with VD and TL. Quantitatively, e.g. when $n_{u p f c}=2$, VD is greatly decreases to 0.006 p.u with a percentage of $64.7 \%$ compared to the initial case without FACTS while the percentage in the case where $n_{u p f c}=1$ is only $11.76 \%$. Likewise, TL is decreased nearly to $2.5 \%$ for $n_{u p f c}=2$ and only $1.6 \%$ when $n_{u p f c}=1$.

The influence of one single UPFC on bus voltages and on real losses in each line of the system at the maximum loading and for different system load-ability is depicted in Figure 6, 7 and 8 respectively. From Figure 7 it appears clearly that the majority of real losses minimization effect was occurred in line number 7, exactly where the UPFC device is installed (Case of 1 UPFC, see Table 3). 


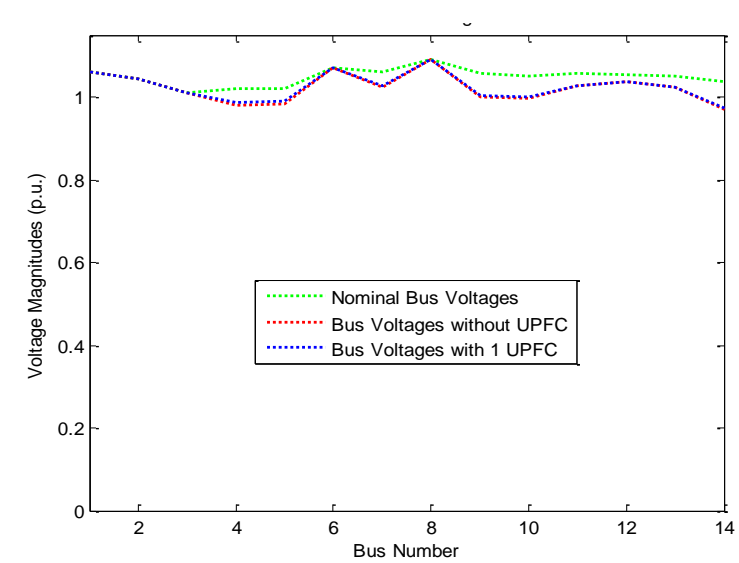

Figure 6. Influence of 1 UPFC on bus voltages

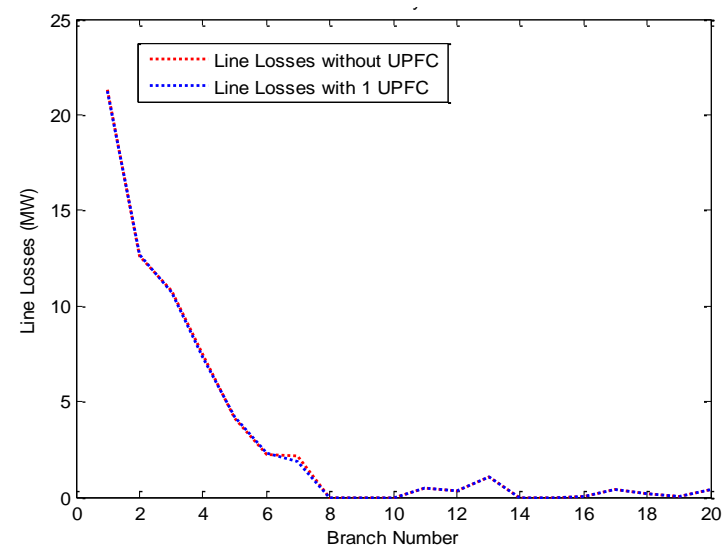

Figure 7. Influence of 1 UPFC on lines real losses

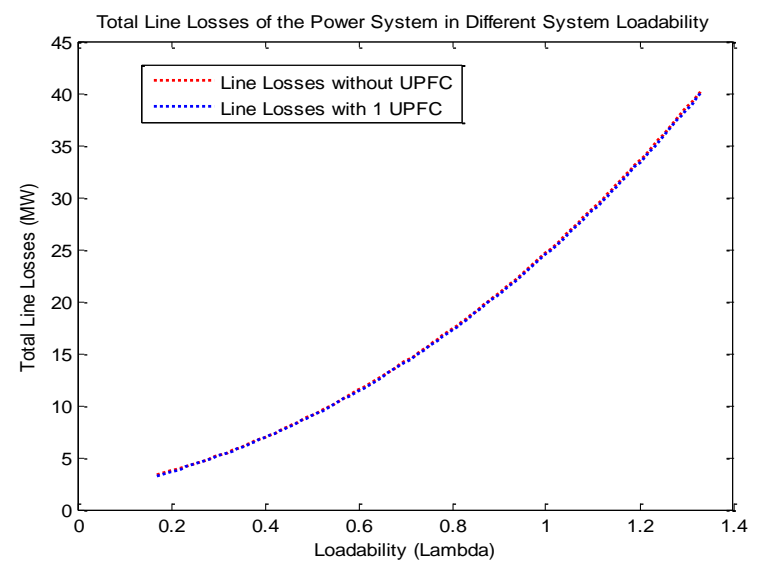

Figure 8. Influence of 1 UPFC on lines real losses for different system load-ability

On the other hand, the results of optimal locations and the three control parameters values for the case of 3 UPFCs as well as the voltage deviation and total losses are compared to that obtained in reference [7]. The comparison results are summarized in Table 5.

Table 5. Comparison of the simulation results for Case $3\left(n_{u p f c}=3\right)$

\begin{tabular}{|c|c|c|c|c|}
\hline & \multicolumn{2}{|c|}{ Obtained results } & \multicolumn{2}{|c|}{ Ref [7] } \\
\hline & Optimal location & $\begin{array}{c}\text { Control parameters } \\
V_{s \rho}=0.163 \text { p.u }\end{array}$ & Optimal location & $\begin{array}{c}\text { Control parameters } \\
V_{s e}=0.189 \text { p.u }\end{array}$ \\
\hline & Branch 1 & $\begin{array}{c}\Phi_{s e}=160.441 \mathrm{deg} \\
I_{s h}=-0.033 \mathrm{p.u} \\
V_{s e}=0.002 \mathrm{p.u}\end{array}$ & Branch 1 & $\begin{aligned} \Phi_{s e} & =66.153 \mathrm{deg} \\
I_{s h} & =0.084 \mathrm{p} . u \\
V_{c} & =0.178 \mathrm{p} . u\end{aligned}$ \\
\hline Optimal locations \& control parameters & Branch 13 & $\begin{array}{c}\Phi_{s e}=333.383 \mathrm{deg} \\
I_{s h}=0.016 \mathrm{p.u} \\
V_{s e}=0.023 \mathrm{p.u}\end{array}$ & Branch 9 & $\begin{array}{c}\Phi_{s e}=240.683 \mathrm{deg} \\
I_{s h}=-0.053 \mathrm{p.u} \\
V_{s e}=0.022 \mathrm{p.u}\end{array}$ \\
\hline & Branch 15 & $\begin{array}{l}\Phi_{s e}=96.888 \mathrm{deg} \\
I_{s h}=-0.028 \mathrm{p} . u\end{array}$ & Branch 14 & $\begin{aligned} \Phi_{s e} & =57.468 \mathrm{deg} \\
I_{s h} & =0.023 \mathrm{p.u}\end{aligned}$ \\
\hline VD (p.u) & & 0.005 & & $0.004^{\text {sh }}$ \\
\hline TL (MW) & & 62.02 & & 61 \\
\hline
\end{tabular}

From Table 5, it appears that despite the existence of some differences between our results and that obtained in reference [7] on the control parameters values, but the locations results of the three UPFCs as well as the voltage deviation and total losses remain near, and that's which validates indirectly our results for the other numbers of UPFCs. 
As it is mentioned previously through Table 4, whenever the number of UPFCs $\left(n_{u p f c}\right)$ installed in the network increases, the voltage deviation (VD) and total losses (TL) decrease untill the case of 4 UPFCs where VD and TL became almost constant despite the increasing of the number of UPFCs. Hence, it is obviously easy to conclude that technically the optimal number of UPFCs devices that must be installed in the 14-bus test power system is 4 UPFCs devices and the optimal locations are the branches: 1, 7, 9 and 12 (i.e. in lines: $1-2,4-5,4-9$ and 6-12) with the corresponding control parameters indicated in Table 3 . It is noted that the optimal number of UPFCs obtained in this paper is based purely on the technical enhancement of the two previous objectives and does not take into account the costs related to the number of UPFCs.

The influence of the 4 UPFCs on bus voltages and on real losses in each line of the system at the maximum loading and for different system load-ability is depicted in Figure 9, 10 and 11 respectively. With comparing these figures with the previous Figures 6, 7 and 8, we observe the great enhancement of voltage profile which became near to the nominal bus voltages with a small value of voltage deviation $(\mathrm{VD}=0.003 \mathrm{pu}$ ), as well as that the total losses became more reduced (around 61.6 MW while with a single UPFC is $63.13 \mathrm{MW}$ ). On the other hand, it is also shown that the application of the proposed approach relationship makes the calculations limited within a narrow space and therefor facilitates greatly the search process and reduces the calculation time.

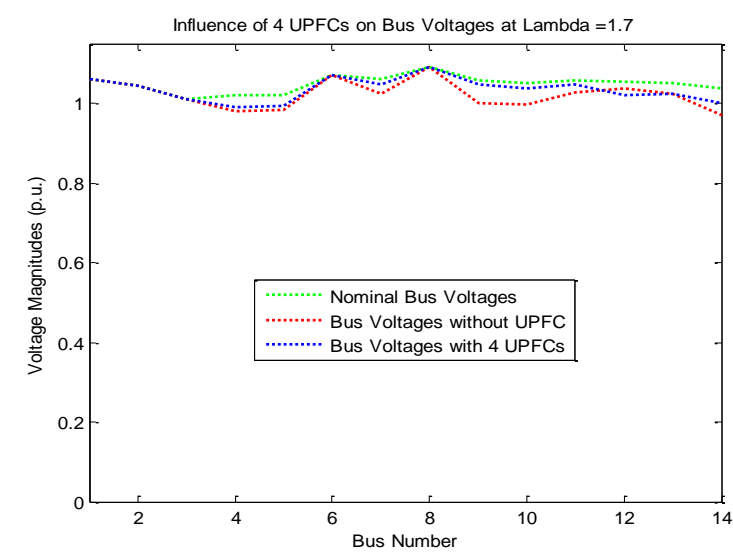

Figure 9. Influence of 4 UPFCs on bus voltages

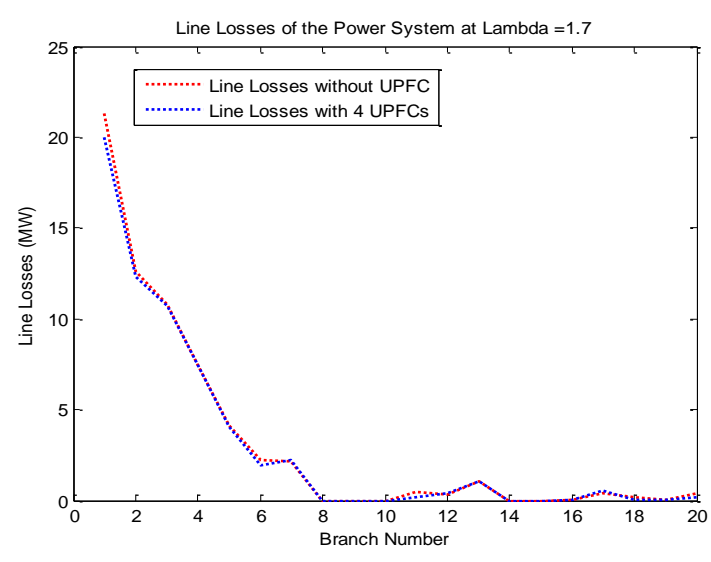

Figure 10. Influence of 4 UPFCs on lines real losses

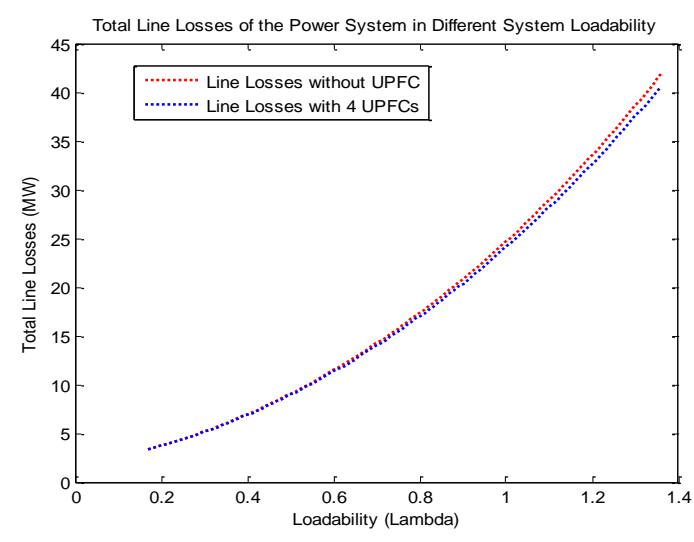

Figure 11. Influence of 1 UPFC on lines real losses for different system load-ability

\section{CONCLUSION}

This paper presents the application of genetic algorithm technique and a proposed approach relationship of identification of maximum number of FACTS devices that can be installed for a given power network in the search process code to determine the optimal number, optimal placement and size of UPFC device in order to minimize voltage deviation and reduce overall real losses in the standard IEEE 14 bus test system. 
The obtained results show that despite the fact that more the number of UPFC devices increase the voltage deviation (VD) and total losses (TL) decrease, there are a limit number of UPFCs devices where these quantities (VD and TL) become constant. This limit number presents technically the optimal number of UPFCs which must be installed. The optimal number of UPFCs devices found in this study is four devices must be installed in branches: 1, 7, 9 and 12. According to these locations, voltage profile became more enhanced and near to the nominal bus voltages and the total lines real losses became more reduced.

On the other hand, it appears that the obtained results are very near to existing papers which validates our results. It is also shown that the application of the proposed relationship facilitates greatly the search process and reduces the calculation time. This work can be extended by relying on the proposed calculation method that can be very useful especially in case of complex and large scale networks, multi-type FACTS devices...etc.

\section{ACKNOWLEDGEMENTS}

Authors would like to thanks the laboratory of electrical engineering of Constantine (LGEC), and the electrical engineering department of Constantine University (Frere Mentouri).

\section{REFERENCES}

[1] A. Oukennou, et al., "Coordinated Placement and Setting of FACTS in Electrical Networks based on Kalai-smorodinsky Bargaining Solution and Voltage Deviation Index," International Journal of Electrical and Computer Engineering (IJECE), vol/issue: 8(6), pp. 4079-4088, 2018.

[2] S. P. Singh, "On-line Assessment of Voltage Stability using Synchrophasor Technology," Indonesian Journal of Electrical Engineering and Computer Science (IJEECS), vol/issue: 8(1), pp. 1-8, 2017.

[3] J. R. Shin, et al., "A new optimal routing algorithm for loss minimization and voltage stability improvement in radial power systems," IEEE Transactions on Power Systems, vol. 22, pp. 648-657, 2007.

[4] P. Kumar, "Enhancement of power quality by an application FACTS devices," International Journal of Power Electronics and Drive Systems (IJPEDS), vol/issue: 6(1), pp. 10-17, 2015.

[5] G. A. Salman, et al., "Implementation Optimal Location and Sizing of UPFC on Iraki Power System Grid (132 kV) Using Genetic Algorithm," International Journal of Power Electronics and Drive System (IJPEDS), vol/issue: 9(4), pp. 1607-1615, 2018.

[6] Mahdi, et al., "Optimal location of FACTS devicesto improve power systems performance," Journal of electrical engineering, vol. 12, pp. 1-8, 2012.

[7] M. Mezaache, et al., "UPFC device: Optimal location and parameter setting to reduce losses in electric-power systems using a genetic algorithm method," Transactions on electrical and electronic materials, vol. 16, 2015.

[8] J. Vanishree and V. Ramesh, "Optimization of size and cost of static Var compensator using dragonfly algorithm for voltage profile improvement in power transmission systems," International journal of renewable energy research, vol. 8, pp. 56-66, 2018.

[9] M. Saravanan, et al., "Application of particle swarm optimization technique for optimal location of FACTS devices considering cost of installation and system loadability," Electric power system research, vol. 77, pp. 276-283, 2007.

[10] R. Benabid, et al., "Optimal location and setting of SVC and TCSC devices using non-dominated sorting particle swarm optimization,” Electric Power Systems Research, vol. 79, pp. 1668-1677, 2009.

[11] M. M. Farsangi, et al., "Multi-objective Var planning with SVC for a large power system using PSO and GA," Proceeding of power system conference \& exposition, pp. 274-279, 2006.

[12] S. Duman, et al., "Optimal power flow using gravitational search algorithm," Energy Conversion and Management, vol. 59, pp. 86-95, 2012.

[13] T. Niknam, et al., "A modified shuffle frog leaping algorithm for multi-objective optimal power flow," Energy journal, vol. 36, pp. 6420-6432, 2011.

[14] H. R. E. H. Bouchekara, et al., "Optimal power flow using the league championship algorithm: a case study of the Algerian power system," Energy conversion and management, vol. 87, pp. 58-70, 2014.

[15] S. Sayah and K. Zehar, "Modified differential evolution algorithm for optimal power flow with non-smoth cost functions," Energy convers manag, vol. 49, pp. 3036-3042, 2008.

[16] J. P. Sridhar and R. Prakash, "Multi-objective Whale Optimization Based Minimization of Loss, Maximization of Voltage Stability Considering Cost of DG for Optimal Sizing and Placement of DG," International Journal of Electrical and Computer Engineering (IJECE), vol/issue: 9(2), pp. 835-839, 2019.

[17] H. Suyono, et al., "Optimization of the Thyristor Controlled Phase Shifting Transformer Using PSO Algorithm," International Journal of Electrical and Computer Engineering (IJECE), vol/issue: 8(6), pp. 5472-5483, 2018.

[18] N. G. Hingorani and L. Gyugyi, "Understanding FACTS: Concepts and technology of flexible AC transmission systems," IEEE press, 1999.

[19] L. Gyugyi, "Unified power flow control concept for flexible AC transmission systems," IEE proceedings, vol. 139, 1992.

[20] E. Acha, et al., "FACTS: Modeling and simulation in power networks," John Wiley and Sons, 2004

[21] Zhang, et al., "Flexible AC transmission systems: Modeling and control," Springer-Verlag Berlin Heidelberg, 2006.

Optimal number and location of UPFC devices to enhence voltage profile and ... (Sekhane Hocine) 
[22] W. L. Fang and H. Ngan, "A robust load flow technique for use in power systems with unified power flow controllers," Electric power system research journal, vol. 53, pp. 181-186, 2005.

[23] E. Ghahremani, "Contribution to wide area control of power systems," Doctoral thesis. Laval University Quebec, 2013.

[24] O. Eseosa and U. Roland, "Genetic Algorithm Based Optimal Placement of Tcsc and Upfc in the Nigeria 330KV Integrated Transmission Line Network at Different Reactive Power Loadings," Journal of Engineering Science and Technology Review, vol. 6, pp. 82-89, 2013.

[25] S. Jigar, et al., "Optimal location of multi-types of FACTS devices using genetic algorithm," International journal of research in computer science, vol. 2, pp. 11-15, 2012.

[26] S. Gerbex, et al., "Optimal location of multi-type FACTS devices in a power system by means of genetic algorithms," IEEE trans power systems, vol/issue: 16(3), pp. 537-544, 2001.

[27] X. P. Wang and Cao, "Genetic algorithms theory, Application and software realization," Xi'an Jiao tong University China, 1998.

[28] Matlab help documentation, "Global optimization toolbox," User’s guide, 2014.

[29] S. R. Najafi, et al., "A novel approach to optimal allocation of SVC using genetic algorithms and continuation power flow," First international Power and Energy Conference PECon, Putrajaya Malaysia, pp. 202-206, 2006.

[30] D. E. Golderberg, "Genetic algorithm in search optimization and machine learning," Addison-Weley publishing company, 1989.

[31] Idris, et al., "Optimal choice of FACTS devices for ATC enhancement using bees algorithm," Power Engineering Conference Australian university AUPEC, pp. 1-6, 2009.

[32] S. Gerbex, "Métaheuristiques appliquées au placement optimale de dispositifs FACTS dans un réseau électrique," Doctoral thesis. Federal institute of technology in Lausane, 2003.

[33] N. Baheshwar and A. Pachori, "Enhancement of voltage stability on IEEE 14 bus systems using static var compensator," International journal of recent research in electrical and electronics engineering (IJRREEE), vol/issue: 2(2), pp. 211-214, 2015.

[34] N. Mithulananthan, et al., "Indices to hopf bifurcations in power systems," In Proc of NAPS-2000, pp. 15-18, 2000.

[35] D. S. Nachimuthu and R. J. Basha, "Reactive power loss optimization for an IEEE 14-bus power system using various algorithms," Istanbul University-Journal of electrical and Electronics Engineering IU-JEEE, vol/issue: 14(1), pp. 1737-1744, 2014.

\section{BIOGRAPHIES OF AUTHORS}
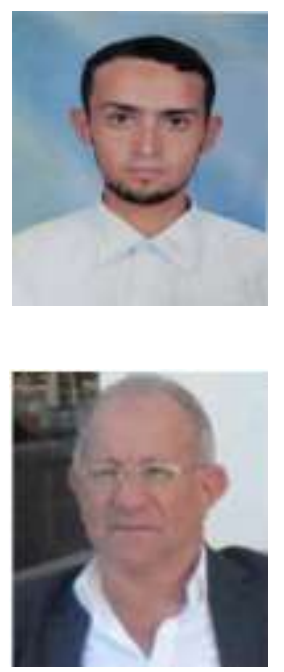

Sekhane Hocine was born in Bouhatem in1985. He received B.S and M.S degrees in electrical engineering from Frere Mentouri University of Constantine, Algeria in 2010 and 2013 respectively. $\mathrm{He}$ is currently $\mathrm{PhD}$ student at the Electrical Engineering Department of Constantine, Algeria. He is integrated in laboratory "LGEC" at Constantine, Algeria. His research interests are Optimal Power Flow, Modeling and control of FACTS systems, System stability. e-mail: docsekhoc@gmail.com

Labed Djamel is a Head of department of electrical engineering of the University Mentouri Constantine, Director of electrical engineering laboratory Constantine LGEC, Director of Research. He received an ingenerate in Electrical from University of Annaba, a Master in Electrical Research Network from the Ecole Polytechnique of Montreal, CANADA, and a PhD in Electrical Engineering from the University Mentouri Constantine. His research activities focus on Dispersed Generation; Analysis of different types of problem quality of electric power caused by renewable energy sources; Various techniques for optimizing the optimal power flow; Stability of groups; Power flow method for DC networks integrated into AC. 